Journal of

APF Command and Staff College

\title{
A Preliminary Study of Yoga Tourism and its Prospects in Nepal
}

Ramesh R. Kunwar,

APF Command and Staff College

Email: kunwar.dr@gmail.com

Netra P. Sharma

Email:netra.acharya@gmail.com

The rhythm of the body, the melody of the mind \& the harmony of the soul create the symphony of life. Iyengar (2005)

\section{Article History}

Received 01 November 2019

Accepted 05 December 2019

\section{Abstract}

This article attempts to reveal the prospects of yoga tourism in Nepal. Yoga is gaining popularity worldwide due to its inherent quality to transform a person from illness to wellness. This is the reason yoga tourism is studied in academia under the umbrella term of wellness tourism. There are potentialities how Nepal can be one of the best destinations for yoga tourism. Nepal is spiritually saturated country being the birthplace of Gautama Buddha and playground of Lord Shiva, the Yogishwara. At the same time, Nepal is a Himalayan country including the highest mountain, Mt. Everest. The cultural heritage is another attraction. The simplicity of people attracts tourists who aim to learn yoga practices while visiting places for refreshment. This article has dealt about how yoga tourism is spreading, what are its theoretical and philosophical background, prospects and potentialities and so on. The major methodology applied in this article is library research, case studies and visiting actual places where yoga tourists from all over the world gather. Yoga retreat survey has revealed actual scenario of yoga tourism. Historicity of yoga philosophy is uncovered using original Classical Sanskrit Cannons. A sample survey identified yoga retreat centers in Kathmandu, the facilities available and potential aspects of tourism and income generation. The finding section documented the actual problems and prospects faced by the hosts, i.e., travel agencies, owners of yoga retreat centers, hoteliers, and yoga masters. The research has reached in conclusion: if right policies and facilities are generated, Nepal will gain a new identity as best destination for yoga tourism in the world. There are potentialities to develop internal yoga tourism as well. One can visualize Nepal being famous and prosperous from yoga tourism and Nepalese people gaining health, wealth and wellbeing by living yogic lifestyle and collecting reputation as yoga masters by guiding tourists into yoga life.

\section{Corresponding Editor}

Ramesh Raj Kunwar

Kunwar.dr@gmail.com

Copyright@2020 Authors

Published by: APF Command and Staff College, Kathmandu, Nepal

ISSN 2616-0242 


\section{Introduction}

The word yoga comes from Sanskrit root 'yuj', which means 'to yoke, to join together or union.' (Fish, 2006, p. 191). This joining is the union of the individual consciousness with the universal consciousness. On a more practical level, yoga is a means of balancing and harmonizing the body, mind and spirit (Lehto, Brown, Chen, \& Morrison, 2006, p. 25; Cheer et al., 2017; Smith and Kelly, 2006). Yoga is about self-inquiry, self-encounter, self-surveillance and dismantling barriers to realizing full human potential (Smith, 2007; in Ponder, Patrick \& Holladay, 2013, p. 28). For many, yoga means spiritual nourishment. But for others, it is just, well, nourishment (Lehto, Brown, Chen, \& Morrison, 2006, p. 27). This is done through the practice of asana, pranayama, mudra, bandha, shatkarma and meditation (Satyananda, 2006, p. 1).

Yoga practitioners are healthy and they look young. Yoga is the fountain of youth. Yoga practices ensure blood flow all over the body, toxin releases and body becomes healthy. A yoga posture makes the spine flexible. As long the spine becomes flexible, the practitioner remains young for long. Yoga is a holistic way of life leading to a state of complete physical, social, mental and spiritual wellbeing and harmony with nature (Taneja, 2014). Yoga is not just repetition of few postures - it is more about the exploration and discovery of the subtle energies of life. In recent time, yoga practitioners are exploring inner and outer world in search of the same. Yoga also can be clinically therapeutic for depression either in combination with meditation (Waelde et al., 2004; in Butler, Waelde, Hastings, Chin, Symons, Marshal et al, 2008, p. 808). Meditation includes a variety of attention-control practices that enable practitioners to focus attention and maintain awareness of the present moment (Waelde, 2004; in Butler et al., 2008). Many studies reported that meditation programs could significantly reduce anxiety and depression, and improve general functioning in a variety of patients (Boorstein, 1983; DeBeri, Davis, \& Reinhard, 1989; Kabat - Zinn, 1995; Shapiro, Schwartz, \& Bonner, 1998; in Butler et al., 2008).

Meditation is proven to help with sleep, stress, anxiety, body images, hot flashes, irritable bowel syndrome, emotion regulation, loneliness, depression, compassion, relationships, self-knowledge, cognitive function, attention, will power, heart disease, inflammation, blood pressure, immune response and pain management (Landau, 2011; Marchant, 2011; Maxted, 2014; Shocker, 2014; in Norman \& Pokerny, 2017, p. 3). Yoga in Hindu tradition is more than physical exercise. It is a multifaceted philosophy, medicine system and way of life. The Asanas, or 'poses', that people perform when they go to their local class are one part of several other practices - including meditation, abstention and liberation - that are considered as a philosophical school in Hinduism (Muddagouni, 2016). That is not to say somehow that yoga belongs only to Hindus or to all Hindus. It is undeniable that yoga has Hindu roots.

In popular understanding, yoga is practiced in two ways: non-physical yoga and physical yoga. Nonphysical yoga - Non-physical yoga is known as Raja Yoga which is a spiritual practice focused on stilling and controlling the mind through meditation. Other branches of non-physical yoga include Bhakti Yoga (Religious devotion), Jnana Yoga (The Path of Knowledge) and Karma Yoga (Discipline of Action). 
Hatha Yoga: Though physical yoga has been connoted as Hatha Yoga, it is also a warm up practice or a preliminary practice for Raj Yoga. Some scholars understanding of Hatha yoga is limited as physical yoga or postural yoga.

It is modern postural yoga in which there is the practice of asanas or physical postures designed to strengthen the body, increase flexibility, and link the breath with movement. Singleton (2010; in Maddox 2015, p. 335) contends that the modern postural forms of yoga are the result of reframing of practices and beliefs frameworks within India itself over the last one hundred fifty years, in response to encounters with modernity and the west (Singleton, 2010; p. 16; in Maddox, 2015).

In Patanjali's Yoga Sutra (Chatarji \& Datta, 1939; in Ponder \& Holladay, 2013, p. 99), the Eight Fold path is referred to ashtanga, which translates as 'Eight Limbs' (ashta - eight, anga - limb). The eightfold path is laid out to seek balance of strength and compassion within the individual (Chopra \& Simon, 2004; in Ponder \& Holladay, 2013, p. 99). The first limb, yamas, represents five ways in which to stop the causes of suffering; they are commonly referred to as 'rules of social behavior' (Farhi, 2000; in Ponder \& Holladay, 2013). The yamas, promote positive interaction with others through peaceful living and honesty. The second limb, niyamas, represents five 'rules of personal behavior'. The observances of niyamas stimulate positive interactions with self through a set of personal ethics (Farhi, 2000). The third limb, asana, engages the corporeal body; physical practice through postures. Asana, means 'seat' or 'posture' and creates strength, flexibility, balance and calm within the body and mind (Desikachar \& Cravens, 1998; in Ponder \& Holladay, 2013). This sereneness leads to positive intentions in social and emotional actions. The fourth limb of yoga, known as pranayama, or conscious breathing (Jois, 2002; in Ponder \& Holladay, 2013). Pranayama is a form of breathing exercise. The other limbs of yoga are explained by the following scholars.

The depending engagement with one's selfhood and the resulting forms of 'ecstasy' (Eliade, 1969) are reflected in Patanjali's account of Ashtanga Yoga, which outlines the various stages or 'limbs' (organ) of the aspirant's achievement. According to Patanjali, these final limbs involve the restraint of the outward orientation of the senses (Pratyahara), the direction of the mind towards a single object (dharana), the linkage of the mind with the object (dhyana), and finally Samadhi, an involvement with the object so complete that nothing except its comprehension is evident (DesikaChar, 1998, p. 70; Whicher, 1998, pp. 190-199; in Smith, 2007, p. 40). However, according to Patanjali, the yamasand niyamasare the rules to purify personal and social behaviors. Patanjali defines yoga (S. Vivekananda) as "a spiritual practice for "restraining the mind-stuff (chitta) from taking various forms (vritti)."

At least three research questions are formulated for this article: what is yoga tourism and how is the existing scenario of it in Nepal? Why Nepal can be a perfect place for yoga tourism? What are the problems and prospects of yoga tourism in Nepal? The article postulates following objectives:

Yoga tourism is gaining popularity all over the world due to its transformative powers. The world population is compelled to eat toxic food and having sedentary life style. Everyone is in need of health, happiness and wellbeing. Yoga offers all these wellness aspects in easiest and organic way. The first objective of this study is to clarify the importance of yoga tourism. The second objective is 
to identify how Nepal can be the best destination for yoga tourism. This objective will analyze the existing scenario and dig out the potentialities. The third objective is to identify the problems and prospects of yoga tourism in Nepal. This study highlights on the concept of yoga, yoga tourism, motivation, transformation from illness to wellness through yogic learning and practices, emergence of yoga tourism in Nepal and Nepal as sacred landscape for yogic activities.

\section{Yoga Tourism}

Yoga tourism is studied under the umbrella term of wellness tourism, which is studied under health care tourism and ultimately, health tourism is studied under transformational tourism. In this way, yoga tourism transforms from illness to wellness, from restless person to peaceful being.

In tourism studies, motivation is very important to attract the visitors. In the study of yoga tourism, the operators follow the costumer motivations; physical motivators such as losing weight or improving flexibility; cultural motivators, related to engaging with the principles of yoga and experiencing different cultures; interpersonal motivators such as desire to meet new people, desire for escapism or spiritual healing; and status and prestige - yoga is fashionable, it is an individualistic, personal experience (Ali - Knight, 2009; in Kelly \& Ensor, 2017).

The transformation of yoga is referred to as yoga tourism. Yoga tourism is defined as travel to destination to engage in the practice of yoga in related activities that will enhance the physical, mental and spiritual wellbeing of the tourists (Ali - Knight, 2009, p. 87). It comes under the domain of special interest of tourism (Ali - Knight, 2009, p. 87) under the domain of special interest of tourism (Ali - Knight \& Ensor, 2017; Sharma \& Nayak, 2019). Therefore, it is a niche market (Ali Kinght \& Ensor, 2017; Sharma \& Nayak, 2019). Yoga tourism is different from mass tourism because it requires tourists to provide intensive devotion to the yoga practices in the destination (Gupta, 2002; Lheto, Brown, Chen, \& Morrison, 2006, p. 27: Kim et al., 2017).

There is plethora of literature available in yoga tourism or related subject in the academia. Scholars have researched on the authenticity of yoga tourism, it's prospects in global scenario and potentials for the future development. Consistency in the literature regarding the concept of wellness tourism is lacking. A confusing array of terms such as "wellness tourism", "health tourism", "health-care tourism", "medical tourism", "holistic tourism", "well-being tourism", and "spa tourism" are used interchangeably, but often describe different concepts. The term "health tourism" can be used as a comprehensive umbrella term that subsumes medical and wellness tourism. Medical tourists primarily travel to cure or treat a certain illness or medical condition. In contrast, wellness tourists go on vacation to maintain or improve their health and well-being (Mu“ller \& Lanz Kaufmann, 2001; in Voigt, Brown, \& Howat, 2011, p. 17). This distinction between "illness" and "wellness" is consistent with recent wellness tourism definitions and typologies (Henderson, 2004; Mu“ller \& Lanz Kaufmann, 2001; Nahrstedt, 2004; Puczko’ \& Bacharov, 2006; Smith and Puczko’, 2008; Voigt, 2010; in Voigt, et. al., 2011).

The destination literature on yoga and yogi tourist has been subsumed by meditation tourism (Smith \& Puczko, 2009), holistic tourism (Smith \& Kelly, 2006 a; Sheldon \& Bushel, 2009), Spa/Health 
tourism (Gustavo, 2010), spiritual tourism (Mansfield \& Machentos, 2009), medical tourism (Sziva 2010). Frequently, yoga tourism is considered a 'niche' under wellness tourism (Smith \& Kelly, 2006). These citations are excerpted from Ponder \& Holladay (2013).

The authors Kelly (2012) and Ali - Knight \& Ensor (2017) show that there is a significant difference between retreat visitors and general visitors in terms of what are often the very personal experiences encountered. The research shows the typical yoga tourist as being predominantly professional females, aged 35-54, with high levels of education and higher than average income. They tend to be spiritual but not religious, interested in vegetarianism and organic food as well as alternative medicines (Ali - Knight \& Ensor, 2017, p. 6). Currently, over 300 million people practice yoga accounting four percent of the worldwide population (Shift, 2016; in Ali - Knight \& Ensor, 2017, p. 4). The transformative power of yoga tourism manifests itself in a desire to actively engage in the building of Bourdieua's (1986; Ali - Knight \& Ensor, 2017, p. 4) positive capitals (psychological, emotional, spiritual). India has recognized yoga as its important sports discipline and placed in the priority list of sports. UNESCO inscribed yoga in international platform as an intangible cultural heritage of humanity. United Nations Organization proclaimed that June 21 would be celebrated as the International Yoga Day to highlight the benefit of yoga to the people at global level.

In the past five decades' cosmopolitan consumers, mostly in the United States, Europe, Japan and Australia, who are attracted to indigenous and Orientalized alternative health and exercise practices, have created a market demand for transnational commercial yoga. This market draws mostly from Hatha Yoga, a style that emphasizes the physical parts of practice; asanas (postures), pranayams (breathing exercises), and pratyahara (abstraction, a preliminary practice to meditation) (Fish, 2006, p. 191). However, here the term pratyahara not only denotes the abstraction, it also denotes to control the sense organs. Yoga is widely believed to provide an avenue to reduce stress, improve breathing, build strength, and gain flexibility (Lehto et al., 2006). Yoga is not only limited to physical wellbeing practices but it also encompasses meditation, mindfulness and spirituality (Bowers \& Cheers, 2017; in Sharma \& Nayak, 2019). It adds in healing from some health related issues such as stress, arthritis, chronic back pain (Lehto et al., 2006). Traditionally, yoga is several thousand years old South Asian philosophy that trains the embodied mind to accept truth through a combination of physical and mental practices (Fish, 2006, p. 191).

\section{Yoga tourism motivation}

Modern age life has given too many new things to humankind. It has made people's lives easier in many ways. However, more than that, it has also increased the stress levels, the complexities and mental pressure under which we keep going on. What we immediately do not realize is the impact of living such a lifestyle on our health. But those who do care about their lives and want to live it the healthy way, what could be a better way to distress from the distresses of life than to relax in the soothing and therapeutic balm of yogic and meditation practices. Many people believe that yoga and meditation are mystic arts that demand complete devotion to the exclusion of everything else. However, the truth is that yoga and meditation are not the hard taskmasters they are often made out to be. Yoga and Meditation can easily be incorporated into our daily lives, requiring no more than a few 
minutes, if not more, every day. Their benefits on the other hand are wide-ranging and restorative (Aggarwal, Guglani, \& Goel, 2008, p. 460).

While there has been no empirical research on yoga tourism, there has been some initial exploration in trade articles on yoga tourist typologies based on travel motives (Spence 2001). While spurred by the broad environmental changes and lifestyle movements, yoga tourism motivations were seen as being derived from three important 'push' factors that served as the drawing factors for people to go for yoga trips and vacations and thus fueled the demand for yoga tourism (The Best of Kerala 2005; Spence 2001; in Lehto et. al., 2006, p. 27). The first push factor is to 'get away from routine work' that could help balance work with wellness and relaxation during or after work. The second push factor is to 'seek an authentic yoga experience' in which yoga lovers look forward to quality and specific care and authentic yoga training courses. Travelers in this group tend to be very knowledgeable in the subject area of yoga and practice it frequently. The yoga tours promoted by entities such as the yoga associations and magazines are mostly targeted at this group of travelers (Hill 2004; in Lehto et. al., 2006, p. 27). The third push factor is to 'enjoy yoga fun', which motivates travelers to enjoy yoga as a fun activity while they spend their vacations away from home. Individuals with these motivations constitute the majority of the yoga tourist group; however, they may participate in different activities and travel in various patterns. The escape or 'push' from a mundane, alienating urban environment has been recognized as a major motivating force in tourism; the desire for a healthy lifestyle, which is a significant intrinsic reward of travel, is also a major contributor (Weiler \& Hall, 1992; in Lehto et. al., 2006, p. 27). From this overall framework of SIT, the 'special-ness' of the activities and the 'specialness' of the tourists can be discerned.

Around the mid-1990s, yoga started to hit the mass-market showing up at the front of the airport magazine racks and on television. As yoga's visibility in the international public eye grew, it became an integral part of the marketing opportunity associated with the LOHAS or "Lifestyles of Health and Sustainability (Ray \& Anderson, 2000; in Strauss \& Mandelbaum, 2013, pp. 176-178) consumer sector, with some US dollar 290 billion 2008 (Ray \& Anderson, 2000; in Strauss \& Mandelbaum, 2013, p. 178).

Push factors for yoga existed in human society since time immemorial. Bridhadaranyaka Upanishad records a beautiful anecdote about push factor for yoga. A sage named Yanjyavalkya wants his wife Maitreyi to accept all his property and stay at home. However, Maitreyi asks, "Does all this property give me freedom? Does this property help me find liberation? Does anything material help me gain immortality?" The sage replies in negation. He declares that if anyone wants immortality or freedom, one should know who he or she is. One should discover one's own Self by austerity or other spiritual practices (The Brihadaranyak Upanishad 2000, 2.4.5. p. 143-144). A deduction can be made that genuine push factors existed in the society several thousand years before.

\section{Yoga tourism as wellness tourism}

The term yoga tourism is interchangeably used with related terms of wellness tourism such as holistic tourism, spiritual tourism, spa tourism (Smith \& Kelly, 2006). 
Holistic Tourism: Tourism that provides the visitor with a range of activities and/ or treatments, which are aimed at developing, maintaining and improving the body-mind-spirit. Holistic tourism covers the broadest scope of engagement: ranging from weekend hotel-spa breaks that include massage treatments, to intensive month-long yoga retreats in basic conditions in South and South-east Asia (Smith \& Kelly, 2006).

Spiritual Tourism: Tourism, which focuses on the spiritual quest of the individual. This may or may not have a religious affiliation, but it is often likely to include rituals, ceremonies, and traditions that are derived from Eastern religions (e.g., Buddhism, Hinduism) (Smith \& Kelly, 2006).

Yoga Tourism: Tourism which focuses on the union of body, mind and spirit, but which is essentially areligious. Techniques include the practicing of physical asanas, meditation and breathing techniques to strengthen the body, calm the mind, and eventually lead to spiritual enlightenment (Smith \& Kelly, 2006).

Spa Tourism: Tourism, which focuses on the relaxation or healing of the body using water-based treatments, such as pools, steam rooms and saunas. Emphasis tends to be focused on relaxation and health and beauty treatments rather than the spiritual aspects of certain exercises such as yoga. Surroundings are usually sumptuous with pricing schemes to match (Smith \& Kelly, 2006).

Religious Tourism: Tourism, which has as its primary aim the furthering of religious understanding and enlightenment. Most tourists will be closely affiliated to one religion and will actively seek out collective religious experiences, usually centered on meaningful locations, sites or monuments (Smith \& Kelly, 2006).

Geeta, the Hindu scripture, records a broad definition of yoga. It says, "Yoga is the very dexterity of work" (Sworupananda 2004, p. 58). The dexterity of work means doing or involving in any yogic activity so that the law of karma does not create bondage. Yoga transforms the practitioner's activity into an efficient means of freedom. From the very ancient time, yoga was understood in broad sense. There were various forms of yoga such as bhakti yoga, gyana yoga, karma yoga, hatha yoga. At the same time, the term yoga was interchangeably used with these different forms of yoga.

There are innumerable studies on yoga tourism; however, almost none of them have tried to reveal the relation between yoga and tourism. It is important to explore the relation between yoga and tourism because awareness of this relation may inspire more people in yoga tourism. The spirit of yoga is uniting or connecting people with the whole creation. This connection is best possible while people travel places with healthy body and peaceful mind. Yoga tourism offers these very things: travelling places with healthy body and peaceful mind. People visit places, practice yoga and experience this connection. This is the relation of yoga and tourism.

In Ayurveda, there is a proverb about health, which says, 'physical health is accomplished if body movement is ensured, mental health is accomplished if mind remains calm.' The practice of yoga tourism ensures these both conditions. Body movement and mental calmness are best accomplished if a person travels places and practices yoga. The question asked is whether yoga tourism has the 
capacity to transform communities towards enlightenment and acceptance, while building psychological, emotional and spiritual capital (Ponder, Patric, \& Holladay, 2013, p. 98).

Yoga holds innermost opportunities for tourism development (Bowers \& Chheer, 2017; in Sharma \& Nayak, 2019). The practice of yoga during the touristic expedition called yoga tourism (Lehto, 2006). In recent years, the research in yoga tourism is emerging as an important tourism theme (Ali-Knight, 2009; Cheer et al., 2017; Maddox, 2015). Yoga tourists senses a unique kind of emotional experiences in the destination they visit (Aggarwal et al., 2008; in Sharma \&Nayak, 2019). Yoga tourism has emerged and grown with the 'travel to feel well trained. Yoga tourism can be viewed as a subset of wellness tourism (Lehto et al., 2006, p. 25). The phenomenon of yoga tourism is relatively new and academic research in this area is in its infancy stage (Lehtho et al., 2006, p. 26). There is an unfortunate dearth of academic writing in this arena. Pritchald (2011, p. 12; in Ponder Patrick, \& Holladay, 2013, p. 98) posited:

(The) suppression of the emotional in tourism enquiry has produced a relatively sterile scholarship which marginalized and excludes many of the complex emotional and passionate geographies from the knowledge worlds created in the field: worlds of pain pleasure, fear - comfort, hate - love and despair - hope. As early as 1985, the world tourism organization placed yoga within five groups of special interest and active holidays. Under the category of social life and competition (WTO, 1985; in Lehto et al., 2006, p 26). For destinations, yoga tourism is a product concept that is based on celebrating your destination with yoga (Concept of Yoga Tourism: Online; in Lehto et al., 2006, p. 27).

Yoga tourism destination should make use of emotional contents in their offerings and promotions. This technique is applied by numerous destination all over the world to instigate positive emotions. For example, "yoga tourism - a way for healthy living." This argument is supported by a study which found a connection between the emotional content of the advertisement and tourist's motivation and intention to visit a destination (Min et al., 2013; in Sharma \& Nayak, 2018).

Pal (2016) says yoga tourism is an act in which people from all around the world travel to other countries to obtain salvation \& medical care while at the same time touring, vacationing, and fully experiencing the attractions of the countries in which they are visiting. A yoga tourist practices yoga during travel or travels for this purpose (Encyclopedia of Tourism, p. 1036).

According to Kumar (2017), yoga tourism has witnessed a secure growth in recent years around the world. As the number of the world's population is becoming more aware of health care options and the quality of health care, yoga is becoming a best choice of many tourists. Yoga tourism is a journey of self with transformative capacities on physical, psychological, spiritual and social awareness. Together they integrate mind, body and spirit (Kelly \& Smith, 2009: in Encyclopedia of Tourism, p. 1036).

Basnet (2016) has written a thesis on 'Types of tourism in Nepal and their prospects' in which he has mentioned the potentiality of five types of tourism: adventure tourism, religious and cultural tourism, 
leisure tourism and business tourism. He has mentioned yoga and meditation can be part of leisure tourism (p. 13), but he has failed to see the prospects of yoga tourism in Nepal.

Yoga tourism can be the catalyst for transformation for a person and society. Ponder \& Holladay (2013) say, shifting perspectives on life through yoga tourism will spur positive transformation that will affect the psychological, emotional and spiritual well-being of individuals and communities with mutual reinforcing positive feedback. Theoretically, as the influence of the creative yoga tourist gains momentum within a community, a critical mass of positive change on community capitals will be realized. The spiritual quest is seen as a more abstract one in which tourists seek meaning, engagement and peace through a variety of different activities, such as meditation, chanting and breathing (Smith and Kelly, 2006, p. 18).

\section{Literature review}

In this review, articles closely related to yoga tourism are taken into account. Lumbini, the birthplace of Gautama Buddha, is developing as popular destination of Meditation tourism. The monasteries from different country run meditation sessions for foreigners. Nepal government has yet to develop meditation centers in Lumbini with the purpose to promote meditation tourism (Sharma, 2019, p. 2). Khanal \& Shimizu $(2018,2019)$ have briefly touched some aspects of yoga tourism in their two research articles. Although, the detail study has not been carried out by any scholar in the case of yoga tourism in Nepal. Similar is the case with yoga tourism. Yoga practices are already flourishing all over the country and there are several hundred yoga retreat centers running. Thousands of tourists arrive in Nepal every year for yoga trekking, practices and other health benefits. However, there is hardly any academic study of yoga tourism in Nepal. Scholars or researchers have yet to be aware of this field of study.

\section{Methodology}

In this research, qualitative methodology is applied to support the arguments raised. Qualitative research is considered best for researching questions such as why and how of human experiences. This method focuses mostly on human elements, concepts and characteristics of social sciences. In this article, qualitative research methodology is applied and textual study is followed mostly to collect theoretical basis of the study and other observations. While studying the development of yoga tourism and while depicting the present scenario at this specific moment of time, diachronic and synchronic approaches are applied respectively. This study quotes yogic philosophy from the original Sanskrit texts. Concisely, this is a qualitative research, which applies diachronic and synchronic approaches quoting Patanjali and other yoga philosopher's teachings from original texts and firsthand experiences from a field visit. In this study, the data has been collected phenomenologically however the researchers could not follow in depth study. Therefore, this study has stated as preliminary study. The second author of this article is yoga master as well who collected first-hand information about yoga retreat centers and yoga trekking in Nepal by field visit. The yoga practitioners who participated in case study are the yoga students of the second author. 


\section{Yoga tourism in Nepal}

Nepal is one of the most important tourist destinations in South Asia. Nepal has been succeeded in offering many different activities to the people visiting Nepal. Its mountains, natural landscapes, cultural landscapes, sacred landscapes, age-old heritage and religious diversity are the major attractions for the tourists. For the first time, tourism was historically introduced in Nepal in 1950 AD. Since then Nepal innovated many different tourism products. Nepal is still in a process of identifying tourism products and developing infrastructures. Tourism has become economic powerhouse for Nepal and Nepalese people.

Tourism statistics shows 1173072 tourists visited Nepal in 2018 (Nepal Tourism Statistics 2018. It is $24.77 \%$ increase in numbers from the previous years. The tourists are categorized into holiday/pleasure, pilgrimage, trekking and mountaineering and other on the basis of their purpose of visit. Historical data showed more than 60 percent of the tourist arrived with purpose of holiday celebration and pleasure. Year 2018 showed higher proportion $(60 \%)$ visited Nepal for holiday and pleasure followed by adventure including trekking \& mountaineering (16\%), pilgrimage (14.4\%) and other purpose (9.6\%) (Nepal Tourism Statistics 2018 (2019), p. 37).

However, it has not been recorded how many tourists visit Nepal for yoga retreats and yoga trekking. Since this trend is increasing overwhelmingly in recent years, it has become essential to record the actual number of tourists and future potentialities of this emerging yoga tourism sector. Nepal aims sustainable development in tourism for fast economic growth. To meet this goal, increasing the number of quality tourists could be an important factor. Exploring the prospects of yoga tourism in Nepal would be worthwhile attempt for the same.

The initial survey about yoga tourism in Nepal has revealed that there are total eighty-five "Yoga and Wellness retreat centers" registered in Kathmandu valley only. There are equal numbers of travel agencies who accept bookings for yoga trekking. Most of them are located in Thamel, the only tourist area in the capital city. There are a little more than one hundred certified yoga masters in Kathmandu. Nearly half of them are graduated from yoga universities in India, others competed yoga-training course run by Nepal Sanskrit University since more than two decades.

The academic study of yoga is running in two universities: Nepal Sanskrit University and Tribhuvan University. Along with yoga comes the Meditation. Buddhist meditation is more popular than every other kind of meditation. A tourist who is interested in yoga is also interested in Meditation. Lumbini Buddhist University, Nepal Sanskrit University and Tribhuvan University run Buddhist philosophy courses, which incorporates meditation as well.

Pokhara is another famous destination for yoga trekking and retreats. While writing on yoga tourism in Nepal, the research article cannot be complete without incorporating Pokhara and other cities (Sauraha, Lumbini) as well. 


\section{Prospects of yoga tourism in Nepal}

In Hindu scriptures, Nepal is depicted as a playground of Pashupatinath who is also known as Lord Shiva. Shiva is the founder of ancient yoga system. Shiva Samhita states that Shiva is also known as Adiyogi, regarded as the patron god of yoga, meditation and arts (Varenne 1976, p. 81). Nepali people grow up listening spiritual teachings of Shiva, Krishna, Rama, Gorakhnath and other renowned yogis of Vedicperiod. The greenery, the pleasant weather, the hillsides, the mountains are the best places for yoga tourism. If a good number of trained yoga instructors can be produced from universities or other authorized institutions, Nepal can be a popular yoga tourism destination in the world. Because, in recent time, people all over the world are aware that yoga and meditation are helpful to relax and explore the spiritual side of oneself. To achieve the same, Nepal, the country of Everest and Buddha, can be the first choice for yoga tourism for many.

In present time, about 20 yogaretreat centers offer yoga training in Kathmandu valley, yoga trekking and other related wellness services and courses as well. These centers have trained and certified yoga instructors. Other yoga centers lack the trained and certified yoga instructor. In recent days, some reputed hotels offer yoga classes to their guests. They too have yet to find certified yoga instructors. The following are the glimpses of popular yoga retreat centers in Kathmandu.

According to Smith and Kelly (2006), a retreat may be defined as a purpose build center, which accommodates its guests for the purpose of learning/improving a body-mind activity (Yoga, Pilates) and/or learning-receiving complementary therapies or treatments whilst there. Group programming of classes is the norm a retreat will usually have no other type of tourism/visitor activity besides that of a holistic nature (p. 20).

\section{Yoga Retreats in Kathmandu}

There are many yoga retreats in and around Kathmandu valley. The most popular of them are: Nepal Yoga Academy, Nepal Yoga Home, Himalayan Yoga, Nepal, Shanti Yoga Ashrama, Mandala Yoga Studio, Sri Aurobindo Yoga Mandir and Hamsada Yoga Ashrama. There are countless yoga centers in Kathmandu, in other major cities and all over Nepal.Some well-known centers are as follows: Naturopathy Hospital, Bhimsengola runs yoga training since 1998 AD (2055 BS). Patanjali Ayurveda Samiti Nepal, Karkhanachowk runs yoga training since 2010. Other yoga centers are Institute of natural medicine, Osho Divine Zone, Tapoban, Kathmandu, Pranamaya yoga community, Thamel, Chetana yoga, Thamel. Some reputed hotels also run yoga training and retreats. Among them, the popular places are Dwarika's hotel Battisputali and Dwarika's resort, Dhulilkel, Chhahari resort, Narayanthan, Kathmandu Eco Hotel, Heritage home hotel and guesthouse, sat-ghumti, Kathmandu, Hotel Nepalaya, Thamel.

The above-mentioned major yoga retreat centers are briefly introduced below: 


\section{Nepal Yoga Academy}

Nepal Yoga Academy (established in 2012) is situated at Changunarayan Municipality, ward no. 5, Chhaya Basti, Chaling. This academy runs regular yoga teachers training on monthly basis. Besides, it runs yoga retreats, yoga detox program, sauna, massage, Ayurveda healings, and corporate yoga and so on. Traditional hatha yoga is followed as a main practice for the trainee.

Among the trainees, almost all are foreigners. Tourists who join the yoga teachers training have to stay four weeks in the yoga academy to complete $200 \mathrm{hrs}$. course. The academy has lodging, food and other facilities equal to good hotels. Each trainee pays $\$ 50$ per day. Those tourists who visit for the retreat, they stay 3 to 7 nights and pay $\$ 70$ per day. According to the academy authority, in average, 50 tourists visit every month. This number fluctuates based on season.

The academy has its website as a main source of contact. Beside the website and social media, the academy does not do any marketing. They say their center is running in full capacity without marketing. However, the academy owners are concerned about unauthorized people running yoga retreats in home stay and any place they find. Once a bad impression is created, it will hinder the flow of yoga tourists in Nepal. It is government's responsibility to regulate authenticity of yoga programs in yoga centers. If the governments run some activities to promote yoga tourism in Nepal, it would flourish even more in future.

Yoga master of this retreat completed his $\mathrm{PhD}$ in yoga from Gurukul Kangri University, India. Gautam and the institution both are associated with International Yoga Alliance. The trainee receives certification of the Alliance.

The main programs of Nepal Yoga Academy:

Yoga teachers training - $200 \mathrm{hrs}$

Yoga teachers training $-500 \mathrm{hrs}$

8 days yogic detox package

Weekend rejuvenation package

4 days Ayurveda pamper package

5 days' yoga deluxe retreat

\section{Nepal Yoga Home}

Nepal Yoga Home (established in 2008) is situated at Tarakeshwor Municipality, ward no. 5, Goldhunga. At the lap of Nagarjun Jungle, Nepal Yoga Home is yoga school, yoga ashrama and yoga studio as well. The programs here are yoga teacher's training (200 hrs. and $500 \mathrm{hrs}$.), yoga retreats, detoxification and massage. International Yoga Alliance USA, Yoga Alliance Australia and World Yoga Alliance, India, certify this yoga center. This center provides Yoga Alliance certification to the trainees who complete the above stated courses. 
The founder of Nepal Yoga Home Completed Master's Degree in Yogic Science and Human Consciousness from Gurukul Kangri University, Haridwar. Per month, 100 tourists visit this retreat. The 200 hrs. yoga teachers training costs \$1400. In most cases, the price depends on the yoga package the tourists buy. This yoga home does not run any marketing activity. The visitors themselves spread the popularity and facilities of this place to their friends and relatives in respective countries. This yoga home has started a hotel in Thamel (Hotel Nepalaya). Tourists can stay in luxury rooms in this hotel and go through the yoga trainings they prefer. Yogi Prakash says: the future of yoga tourism is very bright in Nepal due to its greenery, the simplicity of people, less costly yoga retreats, spiritual culture and environment of Nepal.

\section{Himalayan Yoga, Nepal}

Himalayan Yoga (established in 2007) is situated in Raniban, the northwestern side of Kathmandu valley. Himalayan yoga academy is affiliated to International Yoga Alliance, US. In average eight person visit this academy for $200 \mathrm{hrs}$. yoga training. The cost for yoga training is $\$ 1400$ per person. The academy runs yoga training for eight months every year. The academy also runs yoga retreat programs in which average 60 persons per month visit. The academy's website is the main marketing tool. Besides, they take help of global online websites.

The owner of this academy completed his master's degree in Human Consciousness and yogic science from Gurukul Kangari University, India. Mr. Simkhada sees bright future of yoga tourism in Nepal. Promotion and publicity from government sector and stakeholders would be much helpful. The stakeholders are expected to promote different types of yoga such as Shiva yoga, Patanjali yoga, Buddha yoga, Janaka yoga and so on. The yoga center runs arogyagriha - healing chamber, anna griha, food mess, Chaitanya griha - supreme consciousness chamber, suddhigriha - cleansing chamber and swagatgriha - the welcome home.

\section{Shanti Yoga Ashrama}

Shanti Yoga ashrama (established in 2001) is situated in the lap of Chandragiri, Kathmandu. Nestled in the foothills of the Himalayas with a picturesque view, Shanti Yoga Ashram is the perfect sanctuary to practice yoga and realize the essence of the same. This ashrama focuses classical tantra yoga. This ashrama offers $200 \mathrm{hrs}$. yoga teachers training and yoga retreats. International Yoga Alliance, US certifies this ashrama. Less than a dozen tourists visit this ashrama per month to practice yoga teacher training or enjoy the yoga retreats.

\section{Mandala Yoga studio}

Mandala yoga studio (established in 2014) is situated in Sagarmatha Marga, Thamel, Kathmandu. This center runs yoga teacher training and many yoga retreats programs such as Reiki healing, Sound healing, Ayurveda healing, Spa courses, yoga trekking, hiking and so on. World Yoga Alliance, India certifies this studio. The founder of this yoga studio has completed Master's degree in yoga from Gurukul Kangri University, India. 


\section{Sri Aurobindo Yoga Mandir}

This yoga center (established in 1993) is situated in Chandragiri, Kathmandu. This center follows the integral yoga system of Sri Aurobindo. Besides, this center runs yoga retreats, yoga trekking and Ayurveda facilities to the guests. The yoga instructors are certified by Bihar Yoga Center, India. In average, they have a dozen guests every month.

\section{Hansada Yoga Ashrama}

Though the established date has not been found yet, this yoga ashrama is situated in Banepa. This institution runs yoga training and retreats as well. This ashrama was developed by late yogi Visuddhadeva, the writer of Characterology: The Science of Character. This yoga center is best place for those who prefer rituals, mantra chanting, devotion and spiritual teachings along with yoga practices. This center runs yoga trekking inside and outside the valley as well. The price varies according to yoga package. This center is popular among them who cannot spend much money.

Valmiki Vidyapeeth (Nepal Sanskrit University) runs six months' yoga training program since 1993 AD (2050 BS). This year, Sanskrit Bibhag in Tribhuvan University also runs one-year postgraduate yoga course. In academic courses, the classification of yoga is as following:

1. Astanga Yoga (Patanjali developed eight limbs of yoga - yama, niyama, asana, pranayama, pratyahara, dharana, dhyana, Samadhi)

2. Hatha Yoga (focuses on body postures)

3. Karma Yoga, Bhakti Yoga, Gyan Yoga

4. Sankhya Yoga (prakriti and purusha)

5. Tantra Yoga (incorporates mind, body and spirit)

\section{Yoga trekking in Kathmandu and around}

Nepal Hiking, a travel agency at Naya Bazar, runs regular yoga trekking for foreigners. BMS Adventure Nepalruns yoga trekking to Annapurna base camp, Mount Everest Base camp and many other regions. Hiking Adventure Treks runs yoga trekking in hillsides of Kathmandu and out of valley as well. The popular routs for yoga trekking are on the hillside of Kathmandu valley. One rout starts from Kathmandu - Sundarijal - Chisapani - Nagarkot-Dhulikhel - Namobuddha - Balthali Kathmandu. Another rout starts from Balaju bypass - Tapoban - Panchmane - Tarakeshwor - The waterfall - back to Kathmandu through same rout. Another rout starts from Budhanilkantha (Narayanthan) - Muhanpokhari - Nagi Gompa - Danda Gau - Tare Bhir - Nagi Gompa - and back to Kathmandu. Similarly, yoga trekking starting from Tribhuvan park in Thankot to Chandragiri hill is also a popular rout.

\section{Case study of yoga participants}

Following is the case study of yoga-retreat participants at Osho Divine Zone, Tapoban and Kathmandu. Yoga master Dr. Netra Achraya, the second author of this article, conducted the yoga- 
retreat from 12 September 2019 to 20 September 2019. The participants were from three different countries: America, New Zealand, Hong Kong (China). Below is the sample study of three participants representing each country. During the interview with the participants, they expressed their physical and mental status before they started yoga practices or meditation sessions. They also expressed what kind of changes occurred in their health or mental state due to the practice of yoga and meditation.

\section{Case study 1}

Yoga Participant Cross David (pseudo name) is a US citizen who visited Nepal for yoga practice. Aged 29, he had very little practice of yoga postures beforehand. It was for the first time in life Mr. David joined a yoga-retreat. In the beginning days of the yoga practice, he could practice only basic yoga postures. At the end of the retreat, he was able to practice advanced yoga postures. While asked about the yoga-retreat experience, he expressed his happiness and satisfaction on overall practice. He said, "Body postures were amazing practice for me. After yoga session, I could feel more relaxed and more peaceful."

In the yoga-retreat, he practiced several yoga techniques and yogic life style such as yogic cleansing, yoga postures, breathing exercises and different techniques of meditation. The yogic life style consisted of eating fresh vegetarian food, living in nature, hiking in hillsides/green forest and practicing mindfulness meditation every moment.

He expressed his sense of fulfillment eating fresh food, living in quite place, walking in nature and practicing mindfulness. He realized a sense of rejuvenation at the end of the yoga retreat. He has expressed his commitment of practicing yoga postures and sitting in meditation in a regular basis in coming days. He was thankful to the yoga masters, the yoga home and the nature. It was a non-stop blessing living a yogic life among yogis in the middle of forest.

Before practicing yoga, he was just like any other ordinary human being: full of health problems in body and mind, restlessness, fragmentation, loneliness and a sense of futility of life. After the completion of yoga retreat, he expressed,

I could not believe yoga lifestyle could change everything in my life. My body is becoming more and more healthy and strong. My digestion has improved. My choice of food has changed. I no longer eat meat or drink alcohol. I love vegetarian food now. It gives good health, enough nutrition and a sense of fulfillment as well. I find peace and serenity deep inside me. Yoga, breathing exercise and mediation practices are wonderful techniques developed by ancient yogis, which are equally helpful to us to find health, happiness and see the purpose of living.

\section{Case study 2}

Yoga Participant Issu Teller (pseudo name) is a citizen of New Zealand. She is 24 years old healthy lady. Miss Issu had practiced few yoga postures before joining this yoga retreat. However, she found 
opportunity to practice new yoga postures, which were very much soothing to the body and mind. Her body became more flexible by new postures. While asked about her overall experiences in the yoga retreat, she said,

I learned the proven ways and techniques of health of happiness. The journey to happiness begins from the body. The body is the gross part of a person. One has to keep it flexible and fit. The subtle part is breathing body. One has to practice breathing exercise to regulate the breathing. Breathing is connected to the mind. Once the breathing is regulated, the mind can be regulated. The subtler is the mind body. There is a wonderful meditation technique to keep the mind calm and quiet. The technique is breathing awareness. I learned these all techniques and now I can practice all of them myself. I have realized that a yoga practitioner can always maintain his perfect health and be happy and peaceful no matter what happens around him or her.

Isabel expressed her happiness and satisfaction of learning yoga in the retreat. She further said,

After returning New Zealand, I will continue my yoga practices regularly. I think every person should practice yoga and meditation. The present time is full of pollution and toxic food. Every person has to live in air pollution and eat food that is grown by using so many pesticides. This situation is very risky for health. If we practice yoga and meditation every day, we will be able to release much of the toxins from the body. I am thankful that I am habituated to practice yoga. I will live a yogic life onwards. This was a wonderful yoga experience.

She is a new person because of the yoga practices. She elucidated her feelings as:

Before practicing yoga, I was totally lost somewhere. I never could feel a sense of being. I used to live totally in unawareness. Thankfully, the yoga practices helped me find myself. The peace and happiness that we seek in outside world are already there inside us.

\section{Case study 3}

Yoga Participant Monika (pseudo name) is a Chinese citizen living in Hong Kong. She is 27years' old who is practicing veganism. She avoids all kind of animal products in her diet. She eats only fruits, salad, and sprouts. It is her eating habit since two years. She came to Osho Divine Zone to learn yoga and meditation practices. After learning yogic ways, she realized newness in her body and mind. She expressed her satisfaction as, "Yoga sessions made me feel like a newly born baby. I am so relaxed, refreshed and peaceful. "Before practicing yoga, she used to feel rigidity in her body. She used to be restless for simple reasons or no reasons at all. Many times, she used to feel meaninglessness in her life. After learning yoga and meditation, everything changed for the better.

After successfully completing yoga retreat, she expressed her experience like this: 
The yoga postures made my body flexible. Rigidity is no longer in any part or organ of my body. As my body got relaxation, my mind also got relaxed. I am no longer restless. I feel peace and serenity every day, every moment. I started seeing meaning and purpose in life. Yoga is not only a physical practice. It is spiritual practice as well. It helps us know 'who we are' and for what purpose we are here in this planet as a human being. This is the most important lesson I learned in yoga retreat. We are pure awareness. We are already enlightened beings. Being in peace and happiness is our nature. Developing compassion towards all living in our nature, once we realize these truths, we feel blessed. We feel a sense of fulfillment in life.

\section{Discussion}

The above study reveals several aspects of Nepal and prospects of yoga tourism. Nepal is a spiritually saturated country. Different forms of yoga are practiced in everyday life of millions of Nepalese people. In the early morning, the Nepalese people take bath for body purification and sit in meditation (Japa) for mental purification then follows the recitation of Geeta or other spiritual texts. The Buddhist population engages in slightly different rituals. For instance, the Buddhist community in Kathmandu valley recites Manjushree Nama-Sangiti in regular basis. However, yoga is an umbrella term for every spiritual practice leading to emancipation from worldly bondages and regaining peace of mind and happiness. Lord Buddha who developed spiritual practices such as Sila (moral conduct), Samadhi (meditation) and Prajna (wisdom) was born in Nepal in 623 BCE. Mythically, Nepal is well known as the playground of Lord Shiva, who is known as the God of Yogis. In the high Himalaya, caves of Nepal, countless sages and saints practiced yogic techniques for health, happiness and longevity of their life.

In Nepal, there are number of traditions reciting and chanting ancient spiritual texts. Almost every people is well known of the stories, history, and myths of ancient Yogis who practices yoga and attained several hundred years of life. Yoga is culture and nature of Nepalese people. Sanskrit is the language in which ancient knowledge on spiritual philosophy and practices are stored. Nepali language is very similar to Sanskrit. It is easy and convenient to learn Sanskrit and be aware of yoga and other spiritual philosophies. Because of the above-mentioned resources and aspects, Nepal can be a significant and popular place for yoga tourism. Nepalese people are spiritually socialized from their very childhood chanting the mantras, reciting sacred texts like various Purana and visiting sacred and secret places.

The case study reveals that foreigners experience wonderful benefits in physical, mental and spiritual levels. They wish to involve in longer courses. They also expect some authentic certification of their yoga training so that they could be yoga trainers in their respective countries.

Resources and capacities are lacking in every aspects of yoga tourism. Available yoga retreats are not enough to accommodate tourists who want to visit Nepal for yoga trekking or training. In this concern, Nepal government may take initiation to build few ideal yoga retreat centers in nearby hillsides of Kathmandu or elsewhere. The yoga masters are not enough to run required yoga classes. Due to lack of manpower, a yoga master visits different retreat centers to train yoga practitioners. 
More education institutions focusing on academic level study of yoga should run. The yoga trekking routs are not well paved. There are not enough tea houses in considerable distance. The tourists have expressed their experience not finding a shop or tea house to buy a bottle of mineral water. To cash the yoga trekking trend, the concerned authorities has to spend some time and invest to develop the minimum required facilities. Observing all these aspects of Nepalese society, one can say with confidence, there is a wide prospect of yoga tourism in Nepal. The researcher suggests the concerned authorities to expand the volume of yoga tourism in Nepal and make it source of employment and income generation. By conducting research in existing literature, first hand survey of yoga retreat centers or trekking routs, meeting the participants, tourists and involved yoga masters, the following conclusions are drawn.

\section{Conclusion}

Yoga tourism is an emerging genre in tourism industry. Nepal may catch the trend as it has deep philosophical, cultural and natural roots and resources matching the exact needs of yoga tourism. Nepal's spiritual heritage reflects in people's beliefs, conventions and devotion of people in search of higher life than mere physical existence. Nepal government or the concerned authorities should develop a clear vision and build up the infrastructures, train the yoga masters and enlarge academic study of yoga tourism in schools and colleges. If the country can produce trained manpower, develop required facilities and formulate yoga-friendly rules and regulations, Nepal can be a best destination of yoga tourism in recent future. Creating awareness of yogic lifestyle in Nepalese people is the first important step that should be taken immediately. It is very essential because the western culture is spreading widely in major cities and it is entering in villages as well. If necessary steps are not taken in developing yogic awareness in villages, there will remain particularly nothing original, there will be nothing at all Nepalese people can take ownership. The prospect of yoga tourism in Nepal is high, but the declining of its original culture, spiritual awareness and yogic lifestyle is also high. Initiation needs to be taken to expand the volume of yoga tourism in Nepal and make it more professional so that it can be a noble source of employment and income generation. By this preliminary study, the authors realized a need of extensive research on yoga tourism in Nepal.

\section{References}

Aggarwal, A. K., Guglani, M., Goel, R. K.(2008). Spiritual and yoga tourism: A case studyon experience a foreign tourists visiting Rishikesh, India. Conference Tourism in IndiaChallenge ahead, 457-464.

Ali - knight, J. \& Ensor, J. (2017). Salute to the sun: An exploration of UK yoga tourist's profiles. Tourism Recreation Research, 42 (4), 448-497.

Basnet, S. (2016). Types of tourism in Nepal and their prospects. Laurea University of Applied Sciences, Karve, (an unpublished thesis for Bachelor's degree). 
Butler et al. (2008). Meditation with yoga, group therapy with hypnosis, and psychoeducation for long-term depressed mood: A randomized pilot trail. Journal of Clinical Psychology, 54 (7),806- 820 .

Fish, A.(2006). The commodification and exchange of knowledge in the case of transnational commercial yoga. International Journal of Cultural Property, 13, 189-206.

Iyengar, B.K.S. (2005). Light on Life: The Yoga Journey to Wholeness, Inner Peace, and Ultimate Freedom. USA: Raiscoast Books.

Jafari, J. \& Xiao (2016). Encyclopedia of Tourism. Switzerland: Springer International Publishing, 1036.

Khanal, B.P., \& Shimizu, T. (2019). Potential of health tourism development in Nepal: Literature review and future view. Journal On Tourism \& Sustainability, 2 (2) 14-29.

Khanal, B.P., \& Shimizu, T. (2019). Strategies for development of yoga, Ayurveda and meditationbest health tourism in Nepal: Using SWOT analysis. Journal of Tourism and Adventure, 2 (1), 85-107.

Kumar, V. (2017). Prospects and challenges of yoga tourism in India and abroad. International Journal of Research on Tourism and Hospitality, 3 (2), 1-4.

Lehto, X.,Brown, S., Chen, Y.,\&Morrison A.(2006). Yoga tourism as a niche within tourism market. Tourism Recreation Research, 31,25- 35.

Maddox, C. B.(2015). Studying at the source: Ashtanga yoga tourism and the search for authenticity in Mysore, India. Journal of Tourism and Cultural Change, 13(4), 330-343.

Nepal Tourism Statistics 2018 (2019). Kathmandu: Ministry of Culture, Tourism and Civil Aviation.

Norman, A. \&Pokorny, J. J. (2017). Meditation retreats: Spiritual tourism well- being interventions. Tourism Management Perspectives, xxx,1- 7.

Pal, J. (2016). Yoga tourism in India. International Journal of Information Movement. 1(8), 1-6.

Ponder, L. M. \& Holladay, P. (2013). The transformative power of yoga tourism. South Carolina National Heritage Corridor, University of Saint Francis, Joliet, Illinois, USA, Date accessed, 29 May, 2019. https://www.researchgate.net/publication/286501602

Satyananda (2006). Asana, Pranayama, Mudra, Bandha. India: Yoga Publication Trust, Bihar.

Sharma, N.P. (2019). Meditation tourism, Buddhist philosophy in practice: A case study of Lumbini, Nepal. The Gaze Journal of Tourism and Hospitality, 11(1), 37-59.

Sharma, P. \&Nayak, J. K.(2018). Do tourists' emotional experiences influence images and intentions in yoga tourism? Tourism Review, DOI10.1108/ TR- 05-2018-0060. 
Smith,S. \& Kelly, C. (2006).Editorial. Wellness tourism. Tourism Recreation Research, 31(1),1 -4.

Smith, M.\& Kelly, C.(2006). Holistic Tourism: Journeys of the self. Tourism Recreation Research, 31(1), 15-24.

Strauss, S. \&Mandelbaum, L. (2013). Consuming yoga, conserving the environment: transcultural discourse on sustainable living. In Hauser, B. (Ed.), Yoga Travelling: Bodily Practice in Transcultural Perspective (PP 175 - 200), Springer.

Swarupananda, Swami (2004). Srimad Bhagavad Gita. Kolkata:AdvaitaAshrama publication.

The Brihadaranyak Upanishad (1951). Madras, India: Sri Ramakrishna Math.

Taneja, D.K. (2014). Yoga and health. Indian Journal of Community Medicine, 39 (2), 68-72.

Vivekananda, S. Patanjal Yoga Sutrani. Patanjali Yoga Sutras. Date accessed 13 October 2019. http://www.hinduonline.co/DigitalLibrary/SmallBooks/PatanjaliYogaSutraSwamiVivekanan daSanEng.pdf

Voigt, C., Brown, G., \& Howat, G. (2011). Wellness tourists: in search of transformation. Tourism Review, 66(1/2), 16-30. doi:10.1108/16605371111127206

Varenne, J. (1976). Yoga and the Hindu Tradition. Chicago, Illinois: The University of Chicago press. 